\title{
UJI MUTU FISIK DAN UJI HEDONIK BODY BUTTER MASERAT BERAS MERAH JATILUWIH
}

\section{(PHYSICAL QUALITY EVALUATION AND HEDONIC TEST ON BODY BUTTER OF JATILUWIH RED RICE MACERATE)}

\author{
N. M. DHARMA SHANTINI SUENA ${ }^{1} \bullet$, HERLEEYANA MERIYANI ${ }^{1}$, NI PUTU UDAYANA ANTARI $^{1}$ \\ ${ }^{1}$ Fakultas Farmasi Universitas Mahasaraswati Denpasar, Jalan Kamboja No. 11A, Denpasar, Indonesia
}

\begin{abstract}
Abstrak: Jatiluwih merupakan salah satu tujuan wisata andalan Kabupaten Tabanan Bali. Beras merah hasil pertanian dari Jatiluwih terkenal sebagai beras merah organik bermutu tinggi. Beras merah dikenal memiliki aktivitas antioksidan yang tinggi, sehingga komoditi tesebut sangat potensial untuk dikembangkan menjadi sediaan body butter. Dengan dasar pertimbangan tersebut peneliti tertarik untuk melakukan penelitian yang bertujuan untuk menguji mutu fisik dan kenyamanan penggunaan melalui uji hedonik body butter maserat beras merah. Formulasi body butter dilakukan dengan membuat empat jenis formula body butter beras merah (F1, F2, F3, F4). Uji mutu fisik yang dilakukan meliputi uji organoleptis, pH, daya serap, daya sebar, homogenitas, dan daya lekat. Uji hedonik dilakukan terhadap aroma, penampilan fisik, tekstur, dan kenyamanan saat menggunakan body butter maserat beras merah. Kenyamanan saat penggunaan body butter meliputi: kemampuan melembabkan kulit, kelengketan saat digunakan, tingkat kesulitan saat dibersihkan, dan kemampuan body butter menyerap dengan baik ke dalam kulit. Hasil penelitian menunjukkan setiap Formula (F1, F2, F3, F4) memiliki kestabilan yang baik. Berdasarkan uji hedonik didapatkan bahwa formula F3 adalah formula yang terbaik dengan total nilai 100 (dari nilai tertinggi 120). Berdasarkan uji mutu fisik, formula yang terbaik adalah formula F3 karena memiliki daya serap paling tinggi $(5,15 \mathrm{ml})$, daya sebar yang baik $(6,12 \mathrm{~cm})$ dan daya lekat yang baik (1,48 detik) yang tidak berbeda bermakna dengan daya lekat produk pembanding.
\end{abstract}

Kata kunci: beras merah, body butter, uji hedonik, uji mutu fisik.

\begin{abstract}
Jatiluwih is one of Tabanan Regency's mainstay tourist destinations. Agricultural rice from Jatiluwih is known as high quality organic red rice. Red rice is known to have high antioxidant activity, so the commodity has the potential to be developed into body butter. On the basis of these considerations, researchers are interested in conducting research that aims to test the physical quality and the comfort of use through hedonic tests of body butter of red rice. Body butter formulation is done by making four types of formula of red rice body butter (F1, F2, F3, F4). Physical quality tests carried out include organoleptic test, pH value, absorption ability, spreading ability, homogeneity, and stickiness. The hedonic test is carried out on aroma, physical appearance, texture, and comfort when using body butter of red rice. Comfortness when using body butter includes: the ability to moisturize the skin, stickiness when used, difficulty level when cleaned, and the ability of the body butter to well absorbed into the skin. The results showed that each formula (F1, F2, F3, F4) had good stability. Based on the hedonic test it was found that the F3 formula was the best formula with a total value of 100 (120 is the highest score). Based on the physical quality test, the best formula was the F3 formula because it had the highest absorption $(5.15 \mathrm{ml})$, good spreading ability $(6.12 \mathrm{~cm})$ and good stickiness $(1.48$ seconds) which is not significantly different from the stickiness of comparative products.
\end{abstract}

Keywords: body butter, brown rice,hedonic test, physical quality test.

\section{PENDAHULUAN}

Pariwisata merupakan komoditi andalan pemerintah daerah Provinsi Bali. Menurut laporan penelitian yang dilakukan oleh Global Wellness Institute (2013) "Wellness tourism is travel associated with the pursuit of maintaining or enhancing one's personal well-being." Wellness tourism tumbuh paling cepat jika dibandingkan dengan industri pariwisata yang lain, karena industri ini bisa mengundang lebih banyak wisatawan sehingga membawa dampak ekonomi yang lebih besar. Wellness tourism juga dapat mendukung pelestarian budaya tradisional, aset alam yang ada, dan dapat mendorong perkembangan kewirausahaan. Beras merah organik hasil pertanian dari Jatiluwih sangat potensial untuk dikembangkan menjadi body butter sebagai salah satu sarana pendukung pengembangan wellness tourism di daerah Tabanan. Dipilihnya sediaan topikal berupa body butter karena kandungan minyak dan vitaminnya yang tinggi sehingga memiliki

•Correspondence email: dharmashantini@unmas.ac.id 
kemampuan yang lebih tinggi dalam menutrisi dan menjaga kelembaban kulit daripada sediaan body lotion. Body butter cocok untuk tipe kulit kering serta bagian kulit yang tebal dan mudah pecah seperti siku, tumit, dan lutut. Body butter juga berfungsi mencegah strechmark akibat kehamilan.

Penelitian ini bertujuan untuk menguji mutu fisik dan persepsi konsumen terhadap empat formula body butter yang telah dibuat, sehingga diperoleh formula terbaik berdasarkan uji mutu fisik dan uji hedonik.

\section{METODE PENELITIAN}

Alat. Alat-alat gelas, $\mathrm{pH}$ indicator, Elmasonic ${ }^{\circledR}$, waterbath, lemari pendingin, corong Buchner, oven, seperangkat alat uji daya lekat, alat uji daya sebar, kaca objek, kertas saring, batang pengaduk, stirer, aluminium foil, vacum rotary evaporator.

Bahan. Maserat biji beras merah, etanol 96\%, virgin coconut oil, asam stearat, cocoa butter, butylated hydroxy toluene (BHT), trietanolamin, cetyl alcohol, steareth-20, nipagin, nipasol, cyclomethicone, gliserin, akuades, fragarance.

\section{Prosedur Penelitian}

Determinasi dan Pengumpulan Bahan. Penelitian diawali dengan determinasi tanaman asal serta pengumpulan dan penyediaan bahan penelitian. Pembuatan maserat dilakukan dengan menggunakan Elmasonik ${ }^{\circledR}$. Lima puluh gram serbuk biji beras merah yang diperoleh dari daerah Jatiluwih, Tabanan, Bali dimaserasi dengan $250 \mathrm{~mL}$ akuades.

Formulasi Body butter. Formulasi body butter dilakukan dengan membuat empat sediaan body butter beras merah sesuai dengan formula pada tabel 1. Pembeda dari keempat formula ini terletak pada pengemulsi asam stearat, cetyl alcohol, steareth-20, serta basis cocoa butter dan virgin coconut oil. Dibedakan pada eksipien pengemulsinya adalah karena pengemulsi memegang peranan penting dalam menjaga kestabilan sistem emulsi pada krim dan juga mempercepat penyerapan dari zat aktif (Safitri et al., 2014). Konsentrasi eksipien dalam formula mengacu pada rentang lazim penggunaan eksipien yang tercantum dalam Handbook of Pharmaceutical Excipients (Rowe et al., 2009) dan eksipien yang divariasikan konsentrasinya berada dalam rentang tersebut. Formula yang dihasilkan kemudian diuji mutu fisiknya dan penerimaan konsumen berdasarkan uji hedonik. Uji ranking mutu dilakukan untuk menentukan formula terbaik diantara semua formula yang telah dihasilkan.

Tabel 1. Formula Body butter Maserat Beras Merah

\begin{tabular}{|c|c|c|c|c|c|}
\hline \multirow[t]{2}{*}{ Nama Bahan } & \multicolumn{4}{|c|}{ Konsentrasi (\%) } & \multirow[t]{2}{*}{ Fungsi } \\
\hline & F 1 & F 2 & F 3 & F 4 & \\
\hline Maserat biji beras merah & 10 & 10 & 10 & 10 & Bahan aktif \\
\hline Asam stearate & 3 & 4 & 5 & 6 & Pengemulsi \\
\hline Trietanolamin & 1 & 1 & 1 & 1 & Pengemulsi \\
\hline Cetyl alcohol & 2 & 3 & 4 & 5 & Pengemulsi; Emollient \\
\hline Gliserin & 1 & 1 & 1 & 1 & Co-solvent; Humektan \\
\hline Steareth-20 & 0,2 & 0,3 & 0,4 & 0,5 & Pengemulsi \\
\hline Cocoa butter & 4 & 3 & 2 & 1 & Basis; Humektan \\
\hline Cyclomethicone & 1 & 1 & 1 & 1 & Emollient; Humektan \\
\hline Virgin Coconut Oil & 15 & 14 & 13 & 12 & Basis minyak; Emollient \\
\hline Nipagin & 0,35 & 0,35 & 0,35 & 0,35 & Pengawet antimikroba \\
\hline Nipasol & 0,2 & 0,2 & 0,2 & 0,2 & Pengawet antimikroba \\
\hline BHT & 0,0075 & 0,0075 & 0,0075 & 0,0075 & Antioksidan \\
\hline Fragrance & 1 & 1 & 1 & 1 & Penambah Aroma \\
\hline Aquadest & 61,125 & 61,0925 & 60,9925 & 60,8925 & Pelarut \\
\hline
\end{tabular}

Uji Stabilitas Mutu Fisik Body butter. Uji stabilitas mutu fisik sediaan body butter dilakukan pada beberapa tahap, yaitu pada hari ke-1 setelah sediaan selesai diformulasi, lalu pada bulan ke-1, ke-2, dan ke-3. Mutu fisik sediaan body butter dibandingkan dengan mutu fisik body butter yang sudah beredar di pasaran pada setiap pengujian. Uji stabilitas mutu fisik yang dilakukan terhadap sediaan body butter adalah uji organoleptik, uji homogenitas, uji $\mathrm{pH}$, uji daya serap, uji daya sebar, dan uji daya lekat.

Uji Hedonik Body butter. Uji hedonik dilakukan terhadap aroma, penampilan fisik, tekstur, dan kenyamanan saat penggunaan body butter. Kenyamanan saat penggunaan body butter meliputi: kemampuan melembabkan kulit, kelengketan saat digunakan, tingkat kesulitan saat dibersihkan, dan 
kemampuan body butter menyerap dengan baik ke dalam kulit. Tujuan uji tersebut adalah untuk mengetahui tingkat kesukaan panelis terhadap produk body butter. Panelis yang digunakan adalah mahasiswa suatu sekolah tinggi di Denpasar sebanyak 30 orang. Panelis diminta untuk memberi nilai menggunakan 7 skala yaitu dari 1-7 $(1=$ sangat tidak suka, $2=$ tidak suka, $3=$ agak tidak suka, $4=$ netral, $5=$ agak suka, $6=$ suka dan $7=$ sangat suka).

Uji ranking Mutu Body butter. Uji ranking mutu dilakukan menggunakan panelis mahasiswa suatu sekolah tinggi di Denpasar yang telah lulus uji keterandalan panelis (uji duo-trio), dengan jumlah sebanyak 30 orang. Panelis diminta untuk mengurutkan sampel berdasarkan beberapa kriteria yaitu: aroma, penampilan fisik, tekstur, kemampuan melembabkan kulit, kelengketan saat digunakan, tingkat kesulitan saat dibersihkan, dan kemampuan body butter menyerap dengan baik ke dalam kulit. Sampel yang paling tinggi mutunya sesuai dengan kriteria yang telah ditentukan diletakkan dalam urutan pertama diikuti dengan sampel yang kurang kuat dan seterusnya.

Pengolahan dan Analisis Data. Data yang diperoleh dari hasil uji daya serap, daya lekat dan daya sebar sediaan body butter selama penyimpanan dianalisis secara statistik menggunakan uji Friedman dengan taraf kepercayaan $95 \%(\alpha=0,05)$. Perbandingan data stabilitas fisik yang diperoleh setiap minggu antar formula dianalisis statistik menggunakan uji Kruskal-Wallis dan uji Mann-Whitney dengan taraf kepercayaan $95 \%(\alpha=0,05)$

\section{HASIL DAN PEMBAHASAN}

Determinasi dan Maserasi. Determinasi tanaman dilakukan di Lembaga Ilmu Pengetahuan Indonesia UPT Balai Konservasi Tumbuhan Kebun Raya "Eka Karya" Bedugul, Bali. Hasil determinasi menunjukkan bahwa jenis tanaman ini adalah benar beras merah. Hasil yang didapatkan adalah sebagai berikut:

$\begin{array}{ll}\text { Kingdom } & \text { : Plantae } \\ \text { Divison } & \text { : Spermatophyta } \\ \text { Sub Divisio } & \text { : Angiospermae } \\ \text { Kelas } & \text { : Monocotyledoneae } \\ \text { Ordo } & \text { : Poales } \\ \text { Suku } & \text { : Poaceae } \\ \text { Marga } & \text { : Oryza } \\ \text { Jenis } & \text { : Oryza glaberrima Steud. }\end{array}$

Determinasi dari suatu tanaman bertujuan untuk mengetahui kebenaran identitas tanaman tersebut, apakah tanaman tersebut benar-benar tanaman yang diinginkan. Dengan demikian kesalahan dalam pengumpulan bahan yang akan diteliti dapat dihindari (Diniatik, 2015).

Maserat beras merah yang didapat dari proses maserasi menggunakan gelombang ultrasonik adalah sebanyak $1400 \mathrm{ml}$ yang digunakan sebagai bahan aktif untuk empat formula body butter Masingmasing formula body butter (F1, F2, F3, F4) menggunakan maserat beras merah sebanyak 350 $\mathrm{mL}$. Keuntungan utama dari ekstraksi dengan bantuan gelombang ultrasonik adalah konsumsi energi yang lebih kecil dan waktu operasi yang lebih singkat. Penggunaan gelombang ultrasonik memungkinkan proses ekstraksi dilakukan pada tekanan dan temperatur rendah, pemakaian bahan baku dan pelarut yang lebih sedikit, tahapan sintesa yang lebih pendek dan secara simultan akan meningkatkan selektifitas akhir, memungkinkan pemakaian bahan baku dan pelarut dengan kemurnian rendah serta meningkatkan keaktifan katalis dan lain-lain (Supardan et al., 2009). Didapatkan maserat beras merah berwarna merah muda dan berbau khas beras merah.

Uji mutu fisik sediaan body butter. Diformulasikan empat jenis sediaan body butter yang selanjutnya disebut F1, F2, F3, dan F4, yang dibuat berdasarkan formula pada tabel 1 . Hasil uji organoleptis terhadap sediaan body butter F1, F2, F3, F4, dan sediaan yang ada di pasaran (pembanding).

Tabel 2. Hasil Uji Homogenitas Body butter

\begin{tabular}{cccccc}
\hline \multirow{2}{*}{ Formula } & \multicolumn{5}{c}{ Hasil Pengujian Homogenitas } \\
\cline { 2 - 6 } & Hari ke-1 & Hari ke-21 & Hari ke-28 & Bulan ke-2 & Bulan ke-3 \\
\hline F1 & Homogen & Homogen & Homogen & Homogen & Homogen \\
\hline F2 & Homogen & Homogen & Homogen & Homogen & Homogen \\
\hline F3 & Homogen & Homogen & Homogen & Homogen & Homogen \\
\hline F4 & Homogen & Homogen & Homogen & Homogen & Homogen \\
\hline Pembanding & Homogen & Homogen & Homogen & Homogen & Homogen \\
\hline
\end{tabular}

Pengujian organoleptis dapat digunakan untuk memperkirakan kestabilan sediaan secara kimia, fisika, maupun biologi. Perubahan warna, bau, dan bentuk, menandakan adanya kemungkinan ketidakstabilan kimia, fisika, dan juga secara biologi akibat aktivitas mikroba. Diperoleh sediaan body butter berbentuk semipadat, berwarna coklat dan 
berbau aloevera (sesuai dengan bau fragrance yang ditambahkan).

Hasil pengujian homogenitas sediaan menunjukkan sediaan body butter F1, F2, F3, dan F4 bertahan homogen sampai pengamatan pada bulan ke-3, demikian juga dengan body butter pembanding (tabel 2.).

Nilai $\mathrm{pH}$ hasil formulasi maupun pembanding berkisar antara 6-7. Pengujian $\mathrm{pH}$ penting untuk mengetahui tingkat keasaman dari sediaan agar tidak mengiritasi kulit. ediaan topikal sebaiknya memiliki pH yang sesuai dengan $\mathrm{pH}$ kulit karena jika sediaan memiliki pH yang terlalu basa maka dapat menyebabkan kulit menjadi kering, sedangkan jika $\mathrm{pH}$ terlalu asam akan menimbulkan iritasi kulit (Suena et al., 2016). Menurut Zulkarnain et al., (2013) nilai pH sediaan harus sesuai dengan pH kulit yaitu antara 4,5-7,0. Masing-masing kelompok uji memenuhi persyaratan $\mathrm{pH}$ untuk sediaan topikal dan sesuai dengan $\mathrm{pH}$ kulit, sehingga aman untuk digunakan.
Uji daya serap bertujuan untuk mengetahui kemampuan sediaan dalam menyerap air. Syarat uji daya serap pada kulit harus mempunyai kelarutan yang sesuai dalam mineral dan air dengan kadar lebih dari $1 \mathrm{mg}$ krim dapat larut dalam $1 \mathrm{ml}$ air (Juwita et al., 2013). Data daya serap dianalisis secara statistik. Uji Kolmogorov-Smirnov menunjukkan data tidak terdistribusi normal, sehingga digunakan Uji Friedman untuk melihat kestabilan daya serap antar waktu pengamatan dan Mann Whitney untuk mengetahui perbedaan antara kelompok uji dan formula pembanding. Disimpulkan daya serap F1, F2, F3, dan F4 stabil selama pengamatan. Hasil uji statistik terhadap perbandingan daya serap sediaan body butter maserat beras merah dengan pembanding disajikan dalam Tabel 4. F1, F3, dan F4 memiliki daya serap yang berbeda bermakna dengan pembanding, walaupun demikian, baik F1, F2, F3, dan F4 telah memenuhi persyaratan daya serap yang baik karena > 1mg/1mL air. F3 dan F4 bahkan memiliki daya serap yang lebih besar daripada pembanding.

Tabel 3 Hasil Uji Statistik terhadap perbandingan Daya Serap Sediaan Body butter Maserat Beras Merah dengan Pembanding

\begin{tabular}{clcl}
\hline No & \multicolumn{1}{c}{ Pengujian } & Signifikansi & \multicolumn{1}{c}{ Keterangan } \\
$\mathbf{1}$ & $\begin{array}{l}\text { Pengujian perbedaan antar daya } \\
\text { serap F1 dengan pembanding }\end{array}$ & $<0,05$ & $\begin{array}{l}\text { Daya serap F1 }(2,62 \mathrm{ml})<\text { daya } \\
\text { serap pembanding }(3,78 \mathrm{ml})\end{array}$ \\
\hline $\mathbf{2}$ & $\begin{array}{l}\text { Pengujian perbedaan antar daya } \\
\text { serap F2 dengan pembanding }\end{array}$ & $>0,05$ & Tidak berbeda bermakna \\
\hline $\mathbf{3}$ & $\begin{array}{l}\text { Pengujian perbedaan antar daya } \\
\text { serap F3 dengan pembanding }\end{array}$ & $<0,05$ & $\begin{array}{l}\text { Daya serap F3 }(5,15 \mathrm{ml})>\text { daya } \\
\text { serap pembanding }(3,78 \mathrm{ml})\end{array}$ \\
\hline $\mathbf{4}$ & $\begin{array}{l}\text { Pengujian perbedaan antar daya } \\
\text { serap F4 dengan pembanding }\end{array}$ & $<0,05$ & $\begin{array}{l}\text { Daya serap F4 }(5,12 \mathrm{ml})>\text { daya } \\
\text { serap pembanding }(3,78 \mathrm{ml})\end{array}$ \\
\hline
\end{tabular}

Daya sebar yang baik menyebabkan kontak antara sediaan dan kulit menjadi luas, sehingga absorpsi bahan aktif ke kulit berlangsung cepat. Daya sebar yang baik juga membantu mempermudah penggunaan body butter. Uji Kolmogorov-Smirnov menunjukkan data daya serap tidak terdistribusi normal, sehingga digunakan Uji Friedman untuk melihat kestabilan daya sebar antar waktu pengamatan dan Mann Whitney untuk mengetahui perbedaan antara kelompok uji dan formula pembanding. Disimpulkan daya sebar F1, F2, F3, dan F4 stabil selama pengamatan. Daya sebar sediaan yang baik berkisar antara 5 sampai $7 \mathrm{~cm}$ (Garg et al., 2002). Hasil Uji statistik perbandingan daya sebar sediaan body butter maserat beras merah dengan pembanding disajikan dalam Tabel 4. Walaupun terdapat perbedaan bermakna antara daya sebar setiap formula dan daya sebar pembanding, namun formula body butter maserat beras merah telah memenuhi persyaratan daya sebar sediaan yang baik.

Tabel 4. Hasil Uji Statistik terhadap perbandingan Daya Sebar Sediaan Body butter Maserat Beras Merah dengan Pembanding

\begin{tabular}{clcl}
\hline No & \multicolumn{1}{c}{ Pengujian } & Signifikansi & \multicolumn{1}{c}{ Keterangan } \\
\hline $\mathbf{1}$ & $\begin{array}{l}\text { Pengujian perbedaan antar daya } \\
\text { sebar F1 dengan pembanding }\end{array}$ & $<0,05$ & $\begin{array}{l}\text { Daya sebar F1 }(7,87 \mathrm{~cm})>\text { daya } \\
\text { sebar pembanding }(3.79 \mathrm{~cm})\end{array}$ \\
\hline $\mathbf{2}$ & $\begin{array}{l}\text { Pengujian perbedaan antar daya } \\
\text { sebar F2 dengan pembanding }\end{array}$ & $<0,05$ & $\begin{array}{l}\text { Daya sebar F2 }(7,72 \mathrm{~cm})>\text { daya } \\
\text { sebar pembanding }(3.79 \mathrm{~cm})\end{array}$ \\
\hline $\mathbf{3}$ & $\begin{array}{l}\text { Pengujian perbedaan antar daya } \\
\text { sebar F3 dengan pembanding }\end{array}$ & $<0,05$ & $\begin{array}{l}\text { Daya sebar F3 }(6,12 \mathrm{~cm})>\text { daya } \\
\text { sebar pembanding }(3.79 \mathrm{~cm})\end{array}$ \\
\hline $\mathbf{4}$ & $\begin{array}{l}\text { Pengujian perbedaan antar daya } \\
\text { sebar F4 dengan pembanding }\end{array}$ & $<0,05$ & $\begin{array}{l}\text { Daya sebar F4 }(5,63 \mathrm{~cm})>\text { daya } \\
\text { sebar pembanding }(3.79 \mathrm{~cm})\end{array}$ \\
\hline
\end{tabular}


Pengujian daya lekat bertujuan untuk mengetahui kemampuan sediaan melekat pada kulit. Semakin baik sediaan melekat pada kulit, maka sediaan dapat memberikan efek terapi yang lebih lama (Ansel, 1989). Uji Kolmogorov-Smirnov menunjukkan data daya lekat tidak terdistribusi normal, sehingga digunakan Uji Friedman untuk melihat kestabilan daya lekat antar waktu pengamatan dan Mann Whitney untuk mengetahui perbedaan antara kelompok uji dan formula pembanding. Disimpulkan daya lekat F1, F2, F3, dan F4 stabil selama pengamatan. Hasil uji statistik perbandingan daya lekat sediaan body butter Maserat Beras Merah dengan Pembanding disajikan dalam Tabel 5. Berdasarkan uji statistik tersebut terdapat perbedaan bermakna antara daya lekat body butter maserat beras merah Formula F1 dan F2 dengan daya lekat produk pembanding. Daya lekat F1 dan F2 lebih kecil dibandingkan daya lekat pembanding.

Tabel 5 Hasil Uji Statistik terhadap perbandingan Daya Lekat Sediaan Body butter Maserat Beras Merah dengan Pembanding

\begin{tabular}{clcl}
\hline No & \multicolumn{1}{c}{ Pengujian } & Signifikansi & \multicolumn{1}{c}{ Keterangan } \\
$\mathbf{1}$ & $\begin{array}{l}\text { Pengujian perbedaan antar daya } \\
\text { lekat F1 dengan pembanding }\end{array}$ & $<0,05$ & $\begin{array}{l}\text { Daya lekat F1 }(0,76 \text { detik })>\text { daya } \\
\text { lekat pembanding }(1,79 \text { detik })\end{array}$ \\
\hline $\mathbf{2}$ & $\begin{array}{l}\text { Pengujian perbedaan antar daya } \\
\text { lekat F2 dengan pembanding }\end{array}$ & $<0,05$ & $\begin{array}{l}\text { Daya lekat F2 }(0,76 \text { detik })>\text { daya } \\
\text { lekat pembanding }(1,79 \text { detik })\end{array}$ \\
\hline $\mathbf{3}$ & $\begin{array}{l}\text { Pengujian perbedaan antar daya } \\
\text { lekat F3 dengan pembanding }\end{array}$ & $>0,05$ & Tidak berbeda bermakna \\
\hline $\mathbf{4}$ & $\begin{array}{l}\text { Pengujian perbedaan antar daya } \\
\text { lekat F4 dengan pembanding }\end{array}$ & $>0,05$ & Tidak berbeda bermakna \\
\hline
\end{tabular}

Dari keseluruhan pengujian mutu fisik dan kestabilan fisik formula body butter maserat beras merah, formula yang terbaik di antara empat formula yang dibuat adalah formula F3 karena memiliki daya serap paling tinggi $(5,15 \mathrm{~mL})$, daya sebar yang baik $(6,12 \mathrm{~cm})$ dan daya lekat yang baik $(1,48$ detik) yang tidak berbeda bermakna dengan daya lekat produk pembanding body butter yang sudah beredar di pasaran.

Uji hedonik dan ranking mutu. Uji hedonik dilakukan terhadap aroma, penampilan fisik, tekstur, dan kenyamanan saat menggunakan body butter maserat beras merah formula F1, F2, F3, dan F4. Kenyamanan saat penggunaan body butter meliputi: kemampuan melembabkan kulit, kelengketan saat digunakan, tingkat kesulitan saat dibersihkan, dan kemampuan body butter menyerap dengan baik ke dalam kulit. Tujuan uji tersebut adalah untuk mengetahui tingkat kesukaan panelis terhadap sediaan body butter maserat beras merah, sehingga diketahui yang formula terbaik yang paling disukai panelis.

Terdapat dua kriteria yang menunjukkan kesamaan (tidak berbeda bermakna) antara F1, F2, F3 dan F4 dari tujuh kriteria yang diuji pada Uji Hedonik. Dua kriteria itu adalah "Aroma" dan "Tingkat kesulitan saat dibersihkan".
Tabel 6. Hasil Uji Statistik Penerimaan Konsumen terhadap Formula Uji

\begin{tabular}{|c|c|c|}
\hline $\begin{array}{c}\text { Kriteria } \\
\text { Pengujian }\end{array}$ & Signifikansi & Keterangan \\
\hline Aroma & 0,326 & $\begin{array}{l}\text { Tidak berbeda } \\
\text { bermakna }\end{array}$ \\
\hline $\begin{array}{l}\text { Penampilan } \\
\text { fisik }\end{array}$ & $<0,001$ & $\begin{array}{l}\text { Penampilan fisik } \\
\text { terbaik adalah F3 } \\
\text { dengan skor } \\
\text { tertinggi } 5,50\end{array}$ \\
\hline Tekstur & $<0,001$ & $\begin{array}{l}\text { Tekstur terbaik } \\
\text { adalah F3 dengan } \\
\text { skor tertinggi } 6,00\end{array}$ \\
\hline $\begin{array}{l}\text { Kemampuan } \\
\text { melembabkan } \\
\text { kulit }\end{array}$ & $<0,001$ & $\begin{array}{l}\text { Kemampuan } \\
\text { melembabkan kulit } \\
\text { terbaik adalah F3 } \\
\text { dengan skor } \\
\text { tertinggi } 5,50\end{array}$ \\
\hline $\begin{array}{l}\text { Kelengketan } \\
\text { saat digunakan }\end{array}$ & 0,010 & $\begin{array}{l}\text { Kelengketan saat } \\
\text { digunakan terbaik } \\
\text { adalah F3 dengan } \\
\text { skor tertinggi } 5,00\end{array}$ \\
\hline $\begin{array}{l}\text { Tingkat } \\
\text { Kesulitan Saat } \\
\text { Dibersihkan }\end{array}$ & 0,062 & $\begin{array}{l}\text { Tidak berbeda } \\
\text { bermakna }\end{array}$ \\
\hline $\begin{array}{l}\text { Kemampuan } \\
\text { diserap Kulit } \\
\text { dengan Baik }\end{array}$ & 0,010 & $\begin{array}{l}\text { Kemampuan diserap } \\
\text { kulit dengan baik } \\
\text { dari F2, F3, F4 } \\
\text { skornya } 5,00\end{array}$ \\
\hline
\end{tabular}


Keempat formula tidak berbeda bermakna secara aroma, karena keempat formula diberikan bahan tambahan aroma (fragrance) yang sama, yaitu aroma Aloe vera. Keempat formula juga memiliki tingkat kesulitan dibersihkan yang sama karena komponen penyusunnya sama, hanya berbeda konsentrasinya. Perbedaan konsentrasi eksipien dalam formula lebih mempengaruhi tekstur dan penampilan fisik sediaan body butter. Hasil uji hedonik terhadap 30 orang panelis dengan tujuh indikator yang ada menunjukan bahwa F3 adalah formula yang paling disukai oleh panelis, yang dapat dilihat pada kurva histogram (Gambar 1.).

Dari kurva histogram ini juga dapat diketahui bahwa panelis menyukai sediaan F3 di semua indikator yang ada. Selanjutnya untuk menunjang hasil pengujian hedonik maka perlu dilanjutkan dengan uji ranking mutu dengan tujuan untuk mengurutkan mutu produk dari yang terbaik dan menghilangkan yang terjelek. Berdasarkan pengujian tersebut diperoleh hasil bahwa formula body butter maserat beras merah yang terbaik adalah formula F3 (Tabel 7). Berdasarkan uji ranking mutu didapatkan bahwa formula 3 menempati ranking tertinggi dengan total nilai 100. Formula F3 mendapatkan skor tertinggi pada lima kriteria yaitu penampilan fisik, tekstur, kemampuan melembabkan kulit, kelengketan saat digunakan dalam arti body butter melekat cukup lama di kulit dan tidak mudah hilang, dan kemampuan diserap kulit dengan baik.

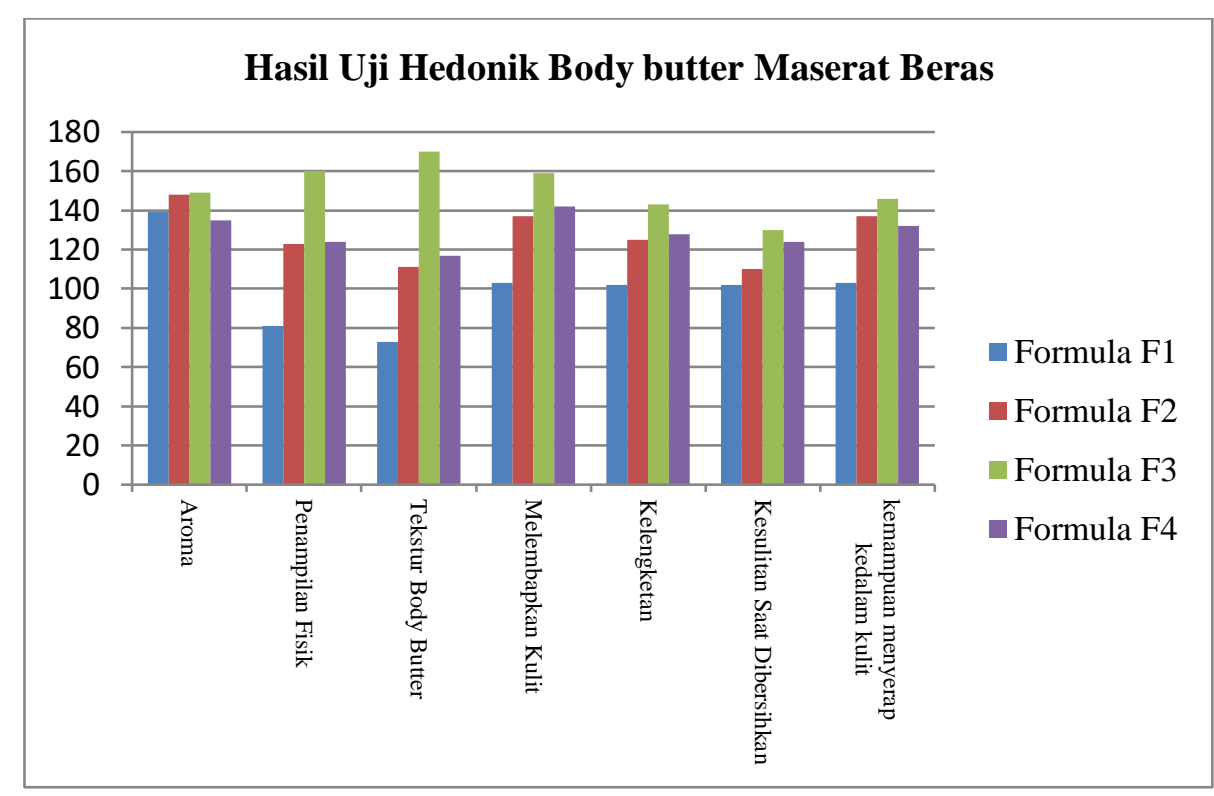

Gambar 1. Histogram Hasil Uji Hedonik Body butter Maserat Beras Merah

Tabel 7. Hasil Uji Ranking Mutu Body butter

\begin{tabular}{cccc}
\hline Formula & Total Skor & Persentase (\%) & Ranking \\
\hline F1 & 48 & 40,0 & 4 \\
\hline F2 & 74 & 61,7 & 3 \\
\hline F3 & 100 & 83,0 & 1 \\
\hline F4 & 77 & 64,2 & 2 \\
\hline
\end{tabular}

\section{KESIMPULAN}

Berdasarkan pengolahan data statistik hasil pengujian stabilitas sediaan body butter maserat beras merah dibandingkan dengan produk pembanding body butter yang beredar di pasaran, selama penyimpanan sampai 3 bulan, maka dapat disimpulkan sebagai berikut:

1. Setiap Formula (F1, F2, F3, F4) memiliki kestabilan yang baik.
2. Berdasarkan uji hedonik dan uji ranking mutu didapatkan bahwa formula F3 adalah formula yang terbaik dengan total nilai 100 (dari nilai tertinggi 120). Berdasarkan uji mutu fisik, formula yang terbaik adalah formula F3 karena memiliki daya serap paling tinggi $(5,15 \mathrm{ml})$, daya sebar yang baik $(6,12 \mathrm{~cm})$ dan daya lekat yang baik (1,48 detik) yang tidak berbeda bermakna dengan daya lekat produk pembanding. 


\section{UCAPAN TERIMA KASIH}

Penelitian ini didanai oleh Akademi Farmasi Saraswati Denpasar (kini Fakultas Farmasi Universitas Mahasaraswati Denpasar) dan didukung dengan baik oleh tenaga kependidikan dan Laboran yang ada.

\section{DAFTAR PUSTAKA}

Ansel, H. C. (1989). Pengantar Bentuk Sediaan Farmasi (F. Ibrahim (ed.); I). UI Press.

Diniatik. (2015). Penentuan Kadar Flavonoid Total Ekstrak Etanolik Daun Kepel (Stelechocarpus burahol (B1.) Hook f. \& Th.) dengan Metode Sprektrofotometri. Kartika Jurnal Ilmiah Farmasi, 3(1), 1-5.

Garg, A., Aggarwal, D., Garg, S., \& Singla, A. K. (2002). Spreading of Semisolid Formulations: An Update. Pharmaceutical Technology North America, 26(9), 84.

Institute, G. W. (2013). The Global Wellness Tourism Economy 2013. Global Wellness Institute. https://globalwellnessinstitute.org/industryresearch/global-wellness-tourism-economy2013/

Juwita, A. P., Yamlean, P. V. Y., \& Edy, H. J. (2013). Formulasi Krim Ekstrak Etanol Daun Lamun (Syringodium isoetifolium). Parmachon Jurnal Ilmiah Farmasi - UNSRAT, 2(02), 8-13.
Rowe, R. C., Sheskey, P. J., \& Quinn, M. E. (2009). Handbook of Pharmaceutical Excipients (6th ed.). Pharmaceutical Press and American Pharmacist Association.

Safitri, N. A., Puspita, O. E., \& Yurina, V. (2014). Optimasi Formula Sediaan Krim Ekstrak Stroberi (Fragaria $\mathrm{x}$ ananassa) sebagai Krim Anti Penuaan. Majalah Kesehatan FKUB, 1, 235-246.

Suena, N. M. D. S., Antari, N. P. U., \& Cahyaningsih, E. (2016). Physical Quality Evaluation Of Body Butter Formulation From Etanol Extract Of Mangosteen (Garcinia Mangostana L.) Rind. Jurnal Ilmu Kefarmasian Indonesia, 15(1), 6369.

http://jifi.farmasi.univpancasila.ac.id/index.ph p/jifi/article/view/455

Supardan, M. D., Ruslan, Satriana, \& Arpi, N. (2009). HIDRODISTILASI MINYAK JAHE (Zingiber officinale Rosc.) MENGGUNAKAN GELOMBANG ULTRASONIK. Reaktor, 12(4), 239-244. https://ejournal.undip.ac.id/index.php/reaktor/a rticle/view/1544/1301

Zulkarnain, A. K., Ernawati, N., \& SUkardani, N. I. (2013). Aktivitas Amilum Bengkuang (Pachyrrizus erosus L. Urban) sebagai Tabir Surya pada Mencit dan Pengaruh Kenaikan Kadarnya terhadap Viskositas Sediaan. Traditional Medicine Journal, 4(2), 2-25. 